\title{
Collaboration Engineering Methodology: Horizontal Extension to Accommodate Project and Program Concerns
}

\author{
Nils L. Randrup \\ AVT Business School \\ nils@ randrup.info
}

\begin{abstract}
A Collaboration Engineering Methodology (CEM) comprises a set of defined, standardized, docu-mented, and discoverable objectives, deliverables, key actions, tools/templates, principles and policies for establishing effective, efficient, satisfying col-laborative work practices for highvalue organi-zational tasks. First-generation CEMs address design and development CE solutions. Existing CEMs, though, focus on the design/build phase, but lack the pre-design and post-build elements that are common to methodologies for adjacent disciplines. We use Design Science Research to situate existing design/build CEMs in the larger context of CE programs and projects. We develop and validate an extended CEM in four phases: 1) Opportunity Assessment, 2) Development, 3) Deployment, and 4) Improvement (ODDI). Phase 1 concerns CE portfolio management and CE project planning; Phase 2 encapsulates existing design/build CEMs; Phase 3 concerns roll-out planning, change management, and implementation; Phase 4 concerns continuous optimization of a deployed work practice. The ODDI model advances CE another step towards becoming a fully realized professional practice, but more research is still required to derive a complete a design theory for CE.
\end{abstract}

\section{Introduction}

Collaboration Engineering is an approach to designing collaborative work practices for high-value tasks, and deploying them to practitioners to execute for themselves without support from collaboration experts [26]. Under certain conditions, teams using collaboration technology attain $70-90 \%$ savings in project cycle times and cut labor hours by $50-70 \%$ while improving the quality of their work products $[7,9,15,19,24]$. These gains, however, were typically only realized in teams lead by expensive collaboration experts such as professional facilitators, so most teams could not attain those benefits. CE emerged as an academic discipline with the goal to make it possible for non-experts to realize the potential benefits of collaboration technology with little or no training on techniques or technologies.

\author{
Robert O. Briggs \\ San Diego State University \\ rbriggs@mail.sdsu.edu
}

When CE research began, most collaboration expertise was tacit - not yet articulated - and difficult to transfer. Over the past 15 years, however, CE researchers have developed collaboration constructs and theories, [e.g. 2, 5]; developed modeling conventions to represent critical aspects of collaboration processes, [10, 25]; and invented new technologies, both to support the professional practices of CEs and to guide non-expert practitioners through well-designed work practices with little or no training [1, 14]. Approaches were developed to measure the quality of collaboration capabilities, processes and outcomes [13, 23]. Various training approaches for CEs and for practitioners - those who lead engineered work practices - were developed and tested [e.g.12].

$\mathrm{CE}$ in the field, however, is still based, in part, on tacit knowledge and trial-and-error, rather than on a formalized professional practice comparable to what exist for well-established practices like Six Sigma, Lean, Project Management, and Balanced Scorecard. A standardized methodology for these practices are well documented and typically found in a "Book of Knowledge", which includes a defined, and discoverable methodology with formalized objectives, deliverables, key actions, tools/templates, principles and policies for conducting the task.

Without standardized methodology, the effectiveness and efficiency of CE projects varies depending on people involved. It limits the ability to train new CEs, to set professional standards, and to evaluate the performance of CEs in the field. Sufficient knowledge now exists, though, to formalize a professional CE methodology.

Toward that end, Kolfschoten and De Vreede [11] devised a five-step approach to designing and building collaborative work practices for practitioners, which we will call the TATAD model (an acronym for its primary activities). For each step, they derived key sub-steps, and for each sub-step they compiled checklists of key design concerns. Building on that work, Randrup and Briggs [23] used the six-layer model of collaboration [2] to reanalyze TATAD into finer-grained steps, then elaborated each step with: a) purposes, b) deliverables, and c) indicators-of-quality for evaluating the performance 
of CEs. TATAD and its descendants are substantial steps toward standardizing a CE methodology.

These works, though, focus primarily on the design/build phase of CE process. Professional engineers, however, conduct design/build in the larger context of engineering programs, and the projects the programs comprise. Before design/build, CEs need to discover and evaluate CE opportunities, select portfolios of projects, and plan each $\mathrm{CE}$ engagement. After design/build, they need to plan and execute rollout, then to conduct continuous improvement engagements.

As a step toward addressing that gap, we propose to extend prior CE methodologies horizontally from a single-phase model to a four-phase model comprising: 1) Opportunity Assessment, 2) Development, 3) Deployment, and 4) Improvement (ODDI) (Error! Reference source not found.). The Opportunity Assessment phase (1) prescribes activities for $\mathrm{CE}$ portfolio management and $\mathrm{CE}$ project planning. The Development phase (2) simply encapsulates the prior CE development models. The Deployment phase (3) prescribes activities for rollout planning, change management, and implementation across an organization. The Improvement phase (4) institutionalizes continuous optimization and improvement of engineered collaborative work practices after initial deployment. The ODDI model thereby situates the development models in the larger context of CE programs and projects.

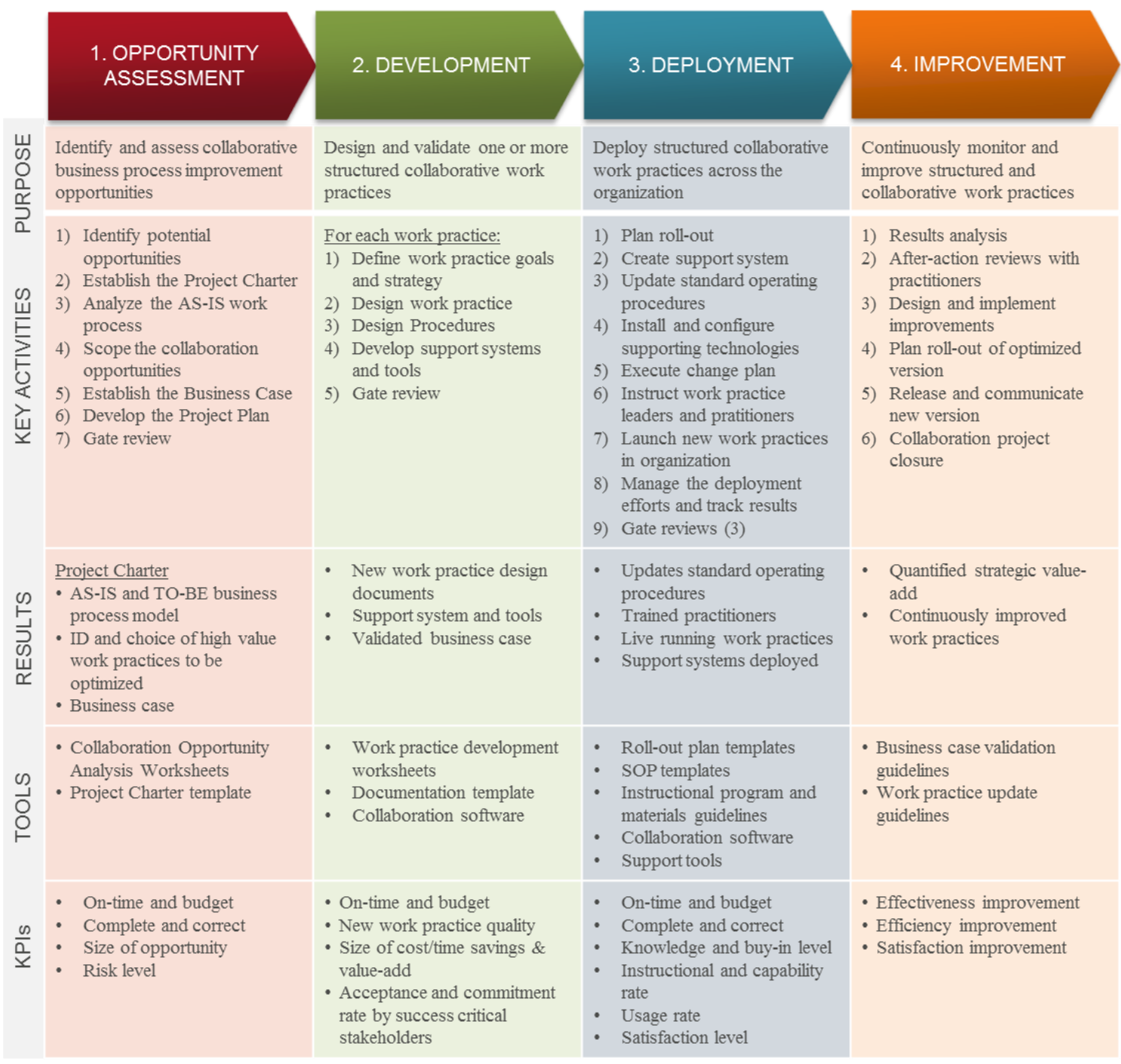

Figure 1. Overview of the ODDI Collaboration Engineering Methodology. Phase 2 encapsulates previous CE design/build methodologies. Phases 1, 3, and 4 extend design/build methodologies horizontally, situating them in the larger context of engineering programs, and the projects the programs comprise. 
This research contributes knowledge toward a CE design theory. A design theory comprises the knowledge practitioners need to implement their own instances of a generalizable solution [8]. One of the eight categories of knowledge composing a design theory is Principles of Implementation. Principles of Implementation are, "A description of processes for implementing the theory in specific contexts. [8, p 322]". Gregor and Jones [8] associate such principles of implementation with the Aristotelian concept, causa efficiens, which in common parlance may be approximated as, "How can we make a useful change happen on purpose?" Our extensions to CE methodology contribute to this category.

In the following sections, we describe our research methods, then describe the phases of ODDI. We discuss their implications and propose next steps for scholarly inquiry.

\section{Research Methods}

We employed a Design Science Research (DSR) approach to develop and validate our methodological solution by following the six DSR research activities described by Peffers, Tuunanen, Rothenberger and Chatterjee [18]: 1) identify a class of unsolved problems; 2) define solution objectives; 3) design/develop a solution; 4) demonstrate the solution, 5) evaluated the solution, and 6) communicate findings. To maintain the relevance of this research, we conducted much of the work in the field in cooperation with several multi-national consulting firms at sites in Sweden, South Africa, and the USA. The practitioners were motivated to participate because they were interested in being among the first to offer professional CE services to their clients. Working with the practitioners gave us access to field venues, where we could observe the research problem in the wild, and gain specific insights about the operational challenges that would constrain our solutions. We initially drew on the existing CE literature and the literatures of Six Sigma [21], Project Management [20], Lean [6] and Balanced Scorecard [17] to clarify the gaps in current CE methodological thinking (Activity 1). The literature showed that more standardized and mature methodologies from other fields tend to share common elements that were not yet derived for CEM. Table 1 contrasts the elements of the original CE methodology (TATAD) with those of the moremature methodologies, highlighting the opportunity for improvements that gave rise to the new ODDI model.

We validated the problem statement and deepened our understanding of it with four train-thetrainer sessions (two in Denver, USA, one in Stockholm, Sweden, and one in Johannesburg, South Africa) with collaboration experts and professional consultants who agreed to participate in the research. Each session lasted one-and-a-half days followed by half-a-day of retrospective analysis and creative problem solving about how existing CEM should be extended. From these experiences, we defined the solution objectives (Activity 2). Over a two-year period, we designed and developed a number of iterations of the ODDI methodology (Activity 3) in design cycles ranging from 2 to 4 months. During each design cycle, we developed, refined, and formalized content to improve to the extended methodology. Each cycle culminated with a trainthe-trainer session for consultants that typically lasted 1.5 days (Activity 4), followed by a half-day of retrospective evaluation (Activity 5). We found proof-of-value and proof-of-use [16] for ODDI when some of the participating consultants adopted the final version of the approach as the foundation for a professional practice, and used it to design and deploy new collaborative work practices for core

Table 1. A Comparison of CE Methodologies with other well-established methodologies. TATAD and Elaborated TATAD lack elements for planning, implementation, and improvement. The ODDI model extends the earlier work to address those gaps.

\begin{tabular}{|l|l|l|l|l|l|}
\hline Field & Methodology & Plan & Create & Implement & Improve \\
\hline Six Sigma & DMAIC & Define & Measure, Analyze & Improve & Improve \\
\hline Lean & PDCA & Plan & Plan & Do & Check, Act \\
\hline $\begin{array}{l}\text { Balanced } \\
\text { Scorecard }\end{array}$ & PUISOI & Prepare & Understand, Identify, Select & $\begin{array}{l}\text { Operationalize, } \\
\text { Implement }\end{array}$ & \\
\hline $\begin{array}{l}\text { Project } \\
\text { Management }\end{array}$ & IPEMCC & $\begin{array}{l}\text { Initiation, } \\
\text { Planning }\end{array}$ & Execution & $\begin{array}{l}\text { Execution, } \\
\text { Monitoring }\end{array}$ & Control, Closure \\
\hline $\begin{array}{l}\text { Collaboration } \\
\text { Engineering } \\
\text { (original) }\end{array}$ & $\begin{array}{l}\text { TATAD, } \\
\text { Elaborated } \\
\text { TATAD }\end{array}$ & & $\begin{array}{l}\text { Task Diagnosis, Activity } \\
\text { Decomposition, Task } \\
\text { ThinkLet choice, Agenda } \\
\text { Building, Design } \\
\text { Validation }\end{array}$ & & \\
\hline $\begin{array}{l}\text { Collaboration } \\
\text { Engineering } \\
\text { (Extended) }\end{array}$ & ODDI & $\begin{array}{l}\text { Opportunity } \\
\text { Assessment }\end{array}$ & Design & Deployment & Improvement \\
\end{tabular}


processes in their clients' organizations.

The following sections present the details of Phases 1, a brief summary of Phase 2, since has been

published elsewhere [4]), followed by the details of Phases 3 and 4.

\section{Phase 1: Opportunity Assessment for Creation or Improvement of Work Practices}

The purpose of the opportunity assessment phase is to identify interesting collaborative issues and opportunities in existing business processes, and the potential value of improving outcomes of interest with a collaboration engineering initiative. The deliverables for this phase include a list of viable collaboration engineering opportunities, prioritized by potential value, and elaborated with documentation such as a business case and a general plan for how to pursue the opportunity. The key activities include:

Step 1. Identify potential opportunities. The purpose of this step is to focus the efforts of CE's where they can return the most value. This step begins with one or more stakeholder needs analysis, similar to what is done during Lean Six Sigma engagements: Voice-of-the-customer (VOS), Voiceof-the-Business (VOB), Voice-of-the-process (VOP), and Voice-of-the-employee (VOE). VOC focus on customer whom the collaboration delivers output and value to. VOB focus on the owners and responsible leadership of the organization. VOP focus on the process owners in which the collaboration takes place. VOE focus on the employees involved in the collaboration process. These analyses use interviews, questionnaires, and conversations to reveal issues and opportunities for improvement. Briggs and Murphy [3] provide interview questions for surfacing $\mathrm{CE}$ opportunities, and criteria for predicting whether a $\mathrm{CE}$ initiative could succeed. The first work product of this step is a list of collaborative issues, prioritized by potential to improve collaborative outcomes. Opportunity assessment centers on the time-on-task, quality-of-work product, and economy of effort for acquiring requisite inputs, collaborative thinking, and execution. Diagnostic assessment of AS-IS processes focuses on inputs, intellective action, and execution. A CE works with stakeholders to develop business cases for the most promising opportunities, and negotiates which should be added to the project portfolio. The final work product is a portfolio of CE projects elaborated with the details of the needs analyses, and prioritized by potential value.

Step 2. Establish the Project Charter. The purpose of this step is to clarify and formalize agreements about key aspects of the project, similar to what is done in the Project Management practice area. Among the work products are a) Problem Statement: unacceptable outcomes that motivates an initiative; b) Purpose Statement: measurable goal/outcomes to be improved; c) Scope: which task elements will and will not be addressed for which stakeholders; d) key stakeholders; e) timing and major milestones; and f) Improvement Potential/Business Case: logic on how the initiative could increase speed, reduce cost, and improve quality. Project charter development proceeds in parallel with all other activities in Phase 1, and typically includes key insights from all steps in this phase.

Step 3. Analyze the AS-IS work process. The purpose of this Step is to clarify the state and quality of an existing work practice, similar to what is done in the Business Process Re-engineering (BPR) and Lean Six Sigma practice area. A variety of process improvement techniques may be brought to bear, for example, walking the process, reviewing existing documentation and metrics, process mapping, and value stream mapping. We find it useful to capture results in a standard SIPOC process model. SIPOC is an acronym for Suppliers, Inputs, Process, Outputs, Customer [21]. The work product for this Step includes information about the process owner, process leader, and process goals. For each goal it lists a) the process b) process leader, c) process goals, each elaborated with performance standards, current performance level, (AS-IS) and desired performance level (TO-BE). It lists the phases for the process, and for each phase it identifies a) suppliers of inputs; b) required inputs; c) key activities; d) outputs, and e) customers - those who use the outputs from the process.

Step 4. Scope the collaboration opportunities. The purpose of this Step is to approximate the relative business potential for a set of $\mathrm{CE}$ opportunities. A CE considers first the frequency, duration, and intensity of collaboration that would be required for a collaborative process to clarify the degree to which a $\mathrm{CE}$ initiative could improve outcomes. The $\mathrm{CE}$ also assess the degree to which stakeholders are ready to change - the likelihood that, if offered an improved collaborative work practice, they would accept it. The CE creates a SIPOC map of the TO-BE process for each opportunity, including collaboration specific information about leaders, participants and resources to clarify the scope of the task. CE develops a Business Opportunity Assessment worksheet for each opportunity to estimate its business potential based on reductions in task cycle times, costs and savings, improvements to the quality of deliverables; and the likely effects of proposed changes on stakeholder satisfaction. The 
Briggs-Murphy instrument provides items for assessing the collaboration for assessing required levels of collaboration and change readiness [3]. Briggs, Reinig and De Vreede [5] provide a validated instrument for measuring stakeholder satisfaction responses to AS-IS and TO-BE processes. The final work product for this Step is a rank-ordered list of CE opportunities prioritized by potential business value, elaborated with rationale for the rank of each.

Step 5. Establish the Business Case. The purpose of this Step is to estimate the ROI or valueadd, the cost associated with a specific CE project. Its key work product is a business case that details the logic of the business reasons for the initiative, establish the priority of the project with management and the project sponsor, demonstrates that sufficient resources are available, and demonstrates a positive relationship among key stakeholders. It details the performance gap the project will address and quantifies the benefits the project should produce. It demonstrates strategic alignment, presents expected financial and non-financial impact, clarifies assumptions, and identifies key success factors. This documentation informs the decision about whether to move forward with a CE project.

Step 6. Develop the Project Plan. The purpose of this Step is to formalize stakeholder expectations for the project, including e.g. leadership, roles, responsibilities, timing, deadlines milestones, resources, costs, deliverables, and constraints. It includes a detailed work breakdown structure and identifies leaders for work packages. It defines what is and is not in the project scope. It identifies risks and potential barriers to success. It includes specific metrics for every outcome of interest. This document guides the control and execution of the CE project.

Step 7. Gate review. For the gate review, the sponsor and other selected key stakeholders evaluate the core deliverables of the project (VOS analysis, project charter, business case and project plan) and the KPIs of the phase. In order to evaluate the performance of the opportunity assessment phase, a set of standard KPIs are used (Table 2). Then the stakeholders approved the output and plans for going forward.

Table 2. KPIs for Phase 1 of a CE project

\begin{tabular}{|l|l|}
\hline KPI & Description \\
On time and & $\begin{array}{l}\text { Opportunity Assessment completed } \\
\text { on time and on budget. }\end{array}$ \\
\hline $\begin{array}{l}\text { Complete and } \\
\text { correct }\end{array}$ & $\begin{array}{l}\text { Opportunity Assessment deliverables } \\
\text { include the required content with the } \\
\text { expected level of correctness }\end{array}$ \\
\hline $\begin{array}{l}\text { Size of } \\
\text { opportunity }\end{array}$ & $\begin{array}{l}\text { Value of the business case for } \\
\text { recommended CE opportunities }\end{array}$ \\
\hline Risk level & $\begin{array}{l}\text { Risk assessment of the business case } \\
\text { and project implementation }\end{array}$ \\
\hline
\end{tabular}

\section{Phase 2: Development of Work Practice}

The purpose of this phase is to design, develop, and test a collaborative work practice for a highvalue organizational task that practitioners can successfully execute with little or no training, gaining benefits similar to those realized in teams led by collaboration experts such as professional facilitators. The deliverables include a fully documented, field tested collaborative work practice comprising a set of procedures for moving through the work packages to create the deliverables to achieve the group goals.

The details of this phase have been published elsewhere [22]. This section therefore provides only a brief overview to establish continuity for the methodology. This phase decomposes into five steps: a) Define work practice goals and strategy; b) Design Work Practice task breakdown structure; c) Design procedures; d) Develop support systems and tools; e) gate review. The phase is not complete until all success-critical stakeholders are willing to accept and commit to the engineered work practice as the standard way to execute the organizational task.

\section{Phase 3: Deployment of Work Practice}

The purpose of the deployment phase is to develop a self-sustaining and growing community of practice around a new collaborative work practice. The deliverables of this phase includes a detailed roll-out plan, work practice support system, updated standard operating procedures (SOPs), ready-to-use software and applications, instructional materials, and a performance tracking data. Its Steps concern planning and executing a rollout of the new work practice across an organization. The key steps for this phase include:

Step 1. Plan roll-out. First, a Roll-out Plan Template, leveraging standard project planning formats, serves as a structure for the Work Practice Deployment Plan. It includes specifies action items for how to a) secure resources; b) map the change process; c) plan communication strategy and tactics to motivate practitioner cooperation in the change process; d) deploy supporting technology; e) plan work practice instructions/training; f) establish succession plans for work practice leading practitioners (assure new practitioners will be available to execute the process as key personnel rotate to other assignments; g) track results obtained after roll-out; and h)Plan, organize, and establish controls for activities needed to oversee and direct the deployment efforts. 
Step 2. Create support system. A support system assists work practice leaders and other practitioners to secure a self-sustaining community of practice. It provides a home and place where practitioners can access work practice content, information and instruction about the work practice and its use. They can access the needed tools, and acquire instructions and training as needed. It serves as a clearing house for feedback about the efficacy, learnability, and acceptability of, and satisfaction with the work practice.

Step 3. Updated Standard Operating Procedures (SOPs). The purpose of this step is to maintain consistency in process quality, and to facilitate practitioner succession. The formalized SOPs pertaining to the work practice should be updated to reflect the new work practice. Existing SOPs should be changed to reflect the new approach. New SOPs should be written where none exists.

Step 4. Install and configure supporting technologies. The purpose of this step is to provide requisite technical infrastructure for practitioners. Software user accounts should be created, and access controls should be adjusted as necessary. Application templates to support the task should be uploaded. Technical support should be arranged.

Step 5. Execute change plan. Based on the communication and change management plan made during the roll-out planning, the communication needs to be produced and executed towards the different target stakeholders. The core focus of the communication is to create awareness about the new improved work practice, of what needs to happen and how to do it. Communication also has to secure motivation and buy-in by practitioners and process owners, as well as secure proper feedback and dialog between the practitioners, CEs, work process owners, and $\mathrm{CE}$ sponsors. It includes an alignment of management and key employees behind the deployment of the work practice; it includes establishing roles and responsibilities for the communication. It includes sending out communication (emails, newsletters, web announcements etc.) and securing feedback from key stakeholders.

Step 6. Instruct work practice leaders and practitioners. The purpose of this step is to transfer knowledge and skills about the new collaborative work practice to work practice leaders and practitioners. The purpose is to build the selfsustaining and growing community of practitioners, who can execute the work processes successfully without assistance from collaboration experts. The format of instructions should be decided (e.g. classroom training vs. online self-paced training with instructional videos, vs. apprenticeship; problem based vs. drill-and-kill). The instructional materials (e.g. work practice description, SOPs, checklists, instructional manual, video instructions, training notes) should be prepared. Instructional and learning evaluation metrics should be designed and implemented. Recruiting approaches should be decided and executed for work practice leaders and key practitioner (e.g. Communications, invitations, and signup confirmations). If needed, facilities for instructional sessions should be booked, instructors selected, instructors trained, training materials produced, and logistics arranged.

Step 7. Launch new work practice in organization. The purpose of this step is to initiate the actual use of the new work practice across the organization. Procedures for scheduling and planning sessions with session leaders are executed, and all practitioners should be granted access to and informed about how to access the support system, the instructional materials, and the software and specific application sessions that will support their work.

Step 8. Manage the deployment efforts and track results. This typically includes activities to set in motion and coordinate the deployment efforts, as well as to secure that communication flows and arising issues are dealt with swiftly. Technical support, help, and maintenance procedures for using the work practice including its collaboration software and other tools should begin. Tracking should begin of relevant data to create reports for the KPIs that motivated the CE initiative. These data would include logging of core session data (date, participants, length etc.), archiving feedback from practitioners who lead sessions, participants, and process customers who received and use the work practice deliverables.

Step 9. Gate reviews. The desired outcome of the gate review is to approval of roll-out plan and approval of the launch. In order to evaluate this phase of the project, the actions needed relate to performing a gate review with the sponsors, and to make adjustments as needed to the deployment plan. Therefore there are 3 relevant gate reviews. The first gate review is performed after the deployment plan is created, and focus on approval of the deployment plan and the corresponding resource investment plans as well as the initial KPIs (on time, on budget, complete and correct deliverables). The second gate review is performed after the first 4-5 sessions of deployment of the work practice is completed, and focus on securing that the first experiences in the organization with the new system and the first KPIs collected (knowledge, buy-in, instructional, capability, satisfaction and task specific KPIs) are aligned with the expectations. The third and final gate review is performed at the conclusion of the 
launch phase with focus on the full range of KPIs (Table 3).

\section{Phase 4: Improvement of Work Practice}

The purpose of this phase is to optimize the new work practice through further improving efficiency and effectiveness of the work practice based on the deployment learnings. Furthermore, the improvement phase should also seek to ensure that the new work practice can be sustained over time and not iterate back. The optimization efforts of this phase could include initiatives to further reduce the costs (e.g. economic, cognitive, political, social, emotional) and time spend on learning and executing the work practice. It could include the reduction of variation of results, reduce the risk of failure, and increase the quality of task deliverables. It is important that the CEs during this phase work directly with work practice leaders, so these practitioners can subsequently implement the optimizations in the organization effectively, as well as take over the responsibility for the continuous improvement task, which will release the CEs from the project, but at the same time sustain continuous improvement support and optimization of the work practice as needed. The key steps of this phase are:

Step 1. Results analysis. After work practice leading practitioners gain experience with the a new work practice, they should work with the CEs and other practitioners to analyze the deployment problems and opportunities, informed by the specified KPI data, qualitative feedback, and a comparison of the results with the expectations identified during phase 1 . This analysis identifies a set of issues, which are prioritized in terms of value of solving vs. cost of solving, and the most important priorities are chosen for an optimization effort.

Step 2. After-action reviews. CEs should conduct smaller qualitative studies (e.g. interviews, focus groups, workshops) with practitioners to unveil root causes and potential solutions to emergent issues, as well as logic to explain shortfalls. The new knowledge acquired in the field is analyzed and summarized to conceive potential improvement ideas. There might also emerge information and insights from these after action reviews to inform further optimizations, based on identified future changes in enterprise processes, policies, organization, strategy, market conditions or technology.

Step 3. Design and implement improvements. CEs should design optimizations to address root causes for prioritized issues with the work practice.
Table 3. KPIs for phase 3 of a CE project

\begin{tabular}{|c|c|}
\hline KPI & Description \\
\hline $\begin{array}{l}\text { On time and } \\
\text { budget }\end{array}$ & $\begin{array}{l}\text { Deployment completed on time and } \\
\text { on budget. }\end{array}$ \\
\hline $\begin{array}{l}\text { Complete and } \\
\text { correct }\end{array}$ & $\begin{array}{l}\text { Deployment deliverables include } \\
\text { the required content with the } \\
\text { expected level of correctness }\end{array}$ \\
\hline Knowledge level. & $\begin{array}{l}\text { Number of practitioners and other } \\
\text { stakeholders who are aware of new } \\
\text { work practice existence divided by } \\
\text { total no. of targeted stakeholders }\end{array}$ \\
\hline Buy-in level & $\begin{array}{l}\text { Number of practitioners and other } \\
\text { key stakeholders who understand, } \\
\text { believe in, and are willing to use of } \\
\text { the new work practice divided by } \\
\text { total no. of targeted stakeholders }\end{array}$ \\
\hline $\begin{array}{l}\text { Instructional } \\
\text { rate }\end{array}$ & $\begin{array}{l}\text { number of instructed or trained } \\
\text { session leaders divided by total } \\
\text { number of targeted session leader } \\
\text { practitioners }\end{array}$ \\
\hline Capability rate & $\begin{array}{l}\text { Number of instances of new work } \\
\text { practice usage divided by total no. } \\
\text { of work practice events }\end{array}$ \\
\hline Usage rate & $\begin{array}{l}\text { Number of instances of new work } \\
\text { practice usage divided by total no. } \\
\text { of work practice events }\end{array}$ \\
\hline Satisfaction level & $\begin{array}{l}\text { The satisfaction level of } \\
\text { participants, session leaders and } \\
\text { work practice owners with the new } \\
\text { work practice itself and its output }\end{array}$ \\
\hline $\begin{array}{l}\text { Task-specific } \\
\text { KPIs }\end{array}$ & $\begin{array}{l}\text { Can include actual process cycle } \\
\text { times, labor hours, and ratings of the } \\
\text { user-friendliness of process, quality } \\
\text { of work practice and supporting } \\
\text { tools, and quality of deliverables }\end{array}$ \\
\hline
\end{tabular}

The revised work practice should be tested by CEs and by practitioners to insure that it works as intended and that the expected improvements materialize. SOPs, the support system, the instructional materials and other core elements in the deployment of the work system should be updated to reflect the optimized version of the work practice.

Step 4. Plan roll-out of optimized version. Communication and deployment plans should be made for the release of the next version of the work practice. Roll-out plans for new releases of optimized work practices are typically smaller than for initial roll-outs, but they must sometimes include most of the same concerns, e.g. making practitioners aware of the update, motivating them to use it, preparing the infrastructure, and making the new version available to practitioners and participants.

Step 5. Release and communicate new version. This includes scheduling and support of the use of the optimized version, as well as communication of the update to all relevant stakeholders. 
Step 6. Collaboration project closure. The last step include performing a final gate review with the sponsors of the CE initiative, and to review the optimizations, their initial results and the overall performance and learnings from the CE project, with the objective being to approve the optimizations and secure the overall learnings. This gate review should be performed after the first 5 uses of the updated version, and should focus on the KPIs collected for new version. The KPIs used for the improvement phase relates mainly to the improvements achieved in effectiveness, efficiency and satisfaction of the optimizations to the work practice vs. the performance of the first version of the work practice deployed (Table 4).

\section{Lessons Learned}

While testing the UDDI methodology in the field, and gathering insights from other Collaboration Engineers, we learned several lessons about successful execution -- or at least ways to avoid making avoidable mistakes.

\section{Project Initiation}

\section{Lesson 1: Define clear, measurable goals for the} CE initiative.

Problem owners usually struggle to articulate the goals for a CE Initiative. When asked about goals, they typically respond instead by naming the process (e.g. "The goal is to do the risk analysis process"), naming an action (“... to assess risks") or naming a deliverable (“... to produce a risk profile.”), which are not goals, but means to achieve goals. If goals are not properly defined, the resulting solution will be off target.

\section{Learning 2: Seek all success critical stakeholders} and bring them to the table.

In one case a two-star general declined a high-value option because, "It would make the secretaries mad, and they are in a position to ruin my career." Success-critical stakeholder turn up in unexpected places, and those who might otherwise oppose the project should be engaged and not ignored.

\section{Learning 3: Scope the project to match its value} potential

$\mathrm{CE}$ can sometimes be an aircraft carrier where a rowboat would do. Some projects don't warrant a full CE initiative. When the potential return for a project is small, a quick and nimble approach is best. All details, steps, and deliverables of the full methodology are valuable on large, complex, high- stakes core organizational processes, but on a small project, one should use only the most critical elements, and skip the rest.

\section{Collaboration design}

\section{Lesson 4: Simplify and automate collaboration process}

The Collaboration design may incorporate a thousand little distractions: a clumsy procedure, an awkward transition, a tedious software feature which create problems for the practitioners using it. When piloting process designs, a CE must watch for these small annoyances, because they can lead to practitioners abandoning it, even if it creates value. Automating the process as much as possible using appropriate collaboration software applications have been very useful to avoid many annoyances, and to simplifying the rest of the process down to its very core.

\section{Implementation effectiveness}

\section{Lesson 5: Motivation and instruction}

Some CE projects fail because efforts to motivate and instruct do not reach all practitioners. Sometimes the only people who know about the solution are those directly involved in the design process. Until all practitioners see how they can attain their own goals by adopting the new practice, and until they are comfortable with how to run the process, the improved processes will not be used in all the cases where it should be.

\section{Conclusions}

This research addresses the problem that $\mathrm{CE}$ methodologies, while useful, were incomplete so the effectiveness and efficiency of CE practices varied widely, and it was difficult to train new CEs to conduct successful CE engagements. Existing methodologies focused on the design/build phase of $\mathrm{CE}$, but did not yet address the larger context of $\mathrm{CE}$ programs and projects. We extended existing methodology by adding phases for discovering, assessing, and selecting among CE opportunities, for planning and executing the rollout of a new engineered collaborative work practice across an organization, and for continuous improvement of a work practice after roll-out. We developed the extensions in cooperation with professional CEs and observed their use of the approach in the field over a two year period. By the end of the research project, the organizations 
had gained the ability to train experienced consultants to conduct $\mathrm{CE}$ engagements in 24-contact-hour courses, and send them into the field to conduct successful engagements.

While these results are promising, this research is not yet complete. The current state of the extended methodology is sufficient for trainees who are already experienced consultants. The documentation of the methodology, however, is not yet sufficiently deep to constitute a complete body of knowledge for CE. More detailed documentation of the logic for the prescribed steps and action items would be useful, as would a set of tools and templates to support each activity in the methodology. Further, methodology is only one of eight categories of knowledge required for a complete design theory. Much of that knowledge exists in the $\mathrm{CE}$ literature and other literatures, but it has not yet been compiled in a form that practitioners can reuse. With this paper, CE takes another step toward becoming a fully realized professional practice, contributing a standardized methodology (ODDI), but more work remains to be done.

\section{Citations}

[1] Briggs, R.O., Kolfschoten, G.L., De Vreede, G.J., Lukosch, S., and Albrecht, C.C., "Facilitator-in-aBox: Process Support Applications to Help Practitioners Realize the Potential of Collaboration Technology", Journal of Management Information Systems, 29(4), 2013, pp. 159-194.

[2] Briggs, R.O., Kolfschoten, G.L., Vreede G.J., D., Albrecht, C., Lukosch, S.G., and Dean, D.L., "A Six Layer Model of Collaboration", in (Editor, 'ed.'^'eds.'): Book A Six Layer Model of Collaboration, M.E. Sharp, Armonk, New York; London, 2014, pp. 211-228.

[3] Briggs, R.O., and Murphy, J.D., "Discovering and Evaluating Collaboration Engineering Opportunities: An Interview Protocol Based on the Value Frequency Model", Group Decision and Negotiation, 20(3), 2011, pp. 315-346.

[4] Briggs, R.O., and Randrup, N., "Evaluating the Performance of Collaboration Engineers", Proceeding of the 48th Hawaii International Conference on System Sciences, 2015, pp. 1-11 (On CD).

[5] Briggs, R.O., Reinig, B.A., and De Vreede, G.J., "The Yield Shift Theory of Satisfaction and Its Application to the Is/It Domain", Journal of the Association for Information Systems, 9(5), 2008, pp. 267-293.

[6] Deming, W.E., "Out of the Crises", MIT Center for Advanced Engineering Study, Cambridge, MA, 1986 ,
Table 4. KPIs for phase 4 of a CE project

\begin{tabular}{|c|c|}
\hline KPI & Description \\
\hline $\begin{array}{l}\text { On time and } \\
\text { budget }\end{array}$ & $\begin{array}{l}\text { Deployment completed on time and } \\
\text { on budget. }\end{array}$ \\
\hline $\begin{array}{l}\text { Complete and } \\
\text { correct }\end{array}$ & $\begin{array}{l}\text { Deployment deliverables include the } \\
\text { required content with the expected } \\
\text { level of correctness }\end{array}$ \\
\hline $\begin{array}{l}\text { Knowledge } \\
\text { level. }\end{array}$ & $\begin{array}{l}\text { Number of practitioners and other } \\
\text { stakeholders who are aware of } \\
\text { optimized work practice existence } \\
\text { divided by total no. of targeted } \\
\text { stakeholders }\end{array}$ \\
\hline Buy-in level & $\begin{array}{l}\text { Number of practitioners and other } \\
\text { key stakeholders who understand, } \\
\text { believe in, and are willing to use of } \\
\text { the optimized work practice divided } \\
\text { by total no. of targeted stakeholders }\end{array}$ \\
\hline Capability rate & $\begin{array}{l}\text { Number of instances of optimized } \\
\text { work practice usage divided by total } \\
\text { no. of work practice events }\end{array}$ \\
\hline Usage rate & $\begin{array}{l}\text { Number of instances of optimized } \\
\text { work practice usage divided by total } \\
\text { no. of work practice events }\end{array}$ \\
\hline $\begin{array}{l}\text { Satisfaction } \\
\text { level }\end{array}$ & $\begin{array}{l}\text { The satisfaction level of participants, } \\
\text { session leaders and work practice } \\
\text { owners with the optimized work } \\
\text { practice itself and its output }\end{array}$ \\
\hline $\begin{array}{l}\text { Task specific } \\
\text { KPIs }\end{array}$ & $\begin{array}{l}\text { Can include improvement in actual } \\
\text { process cycle times of the optimized } \\
\text { work practice or improvement in } \\
\text { labor hours, and ratings of the user- } \\
\text { friendliness of process, quality of } \\
\text { work practice and supporting tools, } \\
\text { and quality of deliverables }\end{array}$ \\
\hline
\end{tabular}

[7] Dennis, A.R., Heminger, A.R., Nunamaker Jr, J.F., and Vogel, D.R., "Bringing Automated Support to Large Groups: The Burr-Brown Experience", Information \& Management, 18(3), 1990, pp. 111121.

[8] Gregor, S., and Jones, D., "The Anatomy of a Design Theory", Journal of the Association for Information Systems, 8(5), 2007, pp. 312-335.

[9] Grohowski, R., Mcgoff, C., Vogel, D., Martz, B. Jr., \& Nunamaker, J.F. Jr., "Implementing Electronic Meeting Systems at Ibm: Lessons Learned and Success Factors", Management Information Systems Quarterly, 14(4), 1990, pp. 368-383.

[10] Kolfschoten, G.L., Briggs, R.O., De Vreede, G.J., Jacobs, P.H., and Appelman, J.H., "A Conceptual Foundation of the Thinklet Concept for Collaboration Engineering", International Journal of HumanComputer Studies, 64(7), 2006, pp. 611-621.

[11] Kolfschoten, G.L., and De Vreede, G.J., "A Design Approach for Collaboration Processes: A Multimethod Design Science Study in Collaboration Engineering", Journal of Management Information Systems, 26(1), 2009, pp. 225-256. 
[12] Kolfschoten, G.L., De Vreede, G.J., and Pietron, L., "A Training Approach for the Transition of Repeatable Collaboration Processes to Practitioners", Group Decision and Negotiation, 20(3), 2011, pp. 347-371.

[13] Kolfschoten, G.L., Lowry, P.B., Dean, D.L., and Kamal, M., "A Measurement Framework for Patterns of Collaboration", in (Briggs, R.O., Vreede G.J., D., and Kolfschoten, G.L., 'eds.'): Report of the Hicss-41 Workshop on Collaboration Engineering, Hawaii International Conference on System Sciences, http://www.hicss.hawaii.edu/Reports.htm, 2008, pp. 5-21.

[14] Kolfschoten, G.L., and Veen, W., "Tool Support for Gss Session Design", Proceedings of the 38th Annual Hawaii International Conference on System Sciences, 2005. HICSS'05., 2005, pp. 1-10 (On CD). [15] Nunamaker, J., Vogel, D., Heminger, A., Martz, B., Grohowski, R., and Mcgoff, C., "Experience at Ibm with Group Support Systems: A Field Study", Decision Support Systems, 5(2), 1989, pp. 183-196.

[16] Nunamaker Jr, J.F., Briggs, R.O., Derrrick, D., and Schwabe, G., "The Last Research Mile: Achieving Both Rigor and Relevance in Information Systems Research ", Journal of Management Information Systems, 32(3), 2015-16, pp. 10-47.

[17] Papalexandris, A., Ioannou, G., Prastacos, G., and Soderquist, K.E., "An Integrated Methodology for Putting the Balanced Scorecard into Action", European Management Journal, 23(2), 2005, pp. 214227.

[18] Peffers, K., Tuunanen, T., Rothenberger, M.A., and Chatterjee, S., "A Design Science Research Methodology for Information Systems Research", Journal of Management Information Systems, 24(3), 2007, pp. 45-77.

[19] Post, B.Q., "A Business Case Framework for Group Support Technology", Journal of Management Information Systems, 9(3), 1993, pp. 7-26.

[20] Project Management Institute, A Guide to the Project Management Body of Knowledge (Pmbok Guide), Project Management Institute, 5th Edition edn, Newton Square, PA, USA, 2013.

[21] Pyzdek, T., and Keller, P.A., The Six Sigma Handbook, McGraw-Hill Education, 2014.

[22] Randrup, N., "Strategic Decision Making Roadmap", Working Paper, AVT Business School, 2015 ,

[23] Randrup, N.L., and Briggs, R.O., "Evaluating the Performance of Collaboration Engineers", in (Editor, 'ed.'^'eds.'): Book Evaluating the Performance of Collaboration Engineers, IEEE Computer Society, Poipu, Kawai, HI, 2015, pp. 600609.

[24] Vogel, D., Nunamaker Jr, J., Martz Jr, W., Grohowski, R., and Mcgoff, C., "Electronic Meeting
System Experience at Ibm", Journal of Management Information Systems, 1989, pp. 25-43.

[25] Vreede, G.J.D., Briggs, R.O., and Kolfschoten, G.L., "Thinklets: A Pattern Language for Facilitated and Practitioner-Guided Collaboration Processes", International Journal of Computer Applications in Technology, 25(2/3), 2006, pp. 140-154.

[26] Vreede, G.J.D., Briggs, R.O., and Massey, A.P., "Collaboration Engineering: Foundations and Opportunities", Journal of the Association for Information Systems, 10(3), 2009, pp. 121-137. 